DOI 10.31489/2021 No3/48-52

UDC 533.6

\title{
STUDY OF AERODYNAMIC CHARACTERISTICS OF A CYLINDRICAL BLADE WITH DEFLECTOR
}

\author{
Tanasheva N.K. ${ }^{1}$, Sakipova S.E. ${ }^{1}$, Minkov L.L. ${ }^{2}$, Bakhtybekova A.R. ${ }^{1 *}$, \\ Shuyushbaeva N.N. ${ }^{3}$, Burkov M.A ${ }^{1}$ \\ 1E.A. Buketov Karaganda University, Karaganda, Kazakhstan, asem.alibekova@inbox.ru \\ ${ }^{2}$ National Research Tomsk State University, Tomsk, Russia \\ ${ }^{3}$ Sh.Ualikhanov Kokshetau University, Kokshetau, Kazakhstan
}

\begin{abstract}
The article discusses some aspects of the renewable energy sources use, in particular, the problem of small wind power. A brief analysis of the development rates of wind energy in the world and in Kazakhstan is presented. The study is devoted to finding ways to optimize the blade of a wind power plant based on the Magnus effect, designed to generate electrical energy at low wind speeds. A cylindrical blade with a turbo-deflector has been developed to ensure independent starting of the blade rotation without the use of additional trigger mechanism. Laboratory tests of a cylindrical blade with a turbo deflector were carried out on a T-I-M wind tunnel at various flow regimes. The obtained dependences of aerodynamic forces on the air flow velocity at different angles of attack are shown.
\end{abstract}

Keywords: cylindrical blade with deflector, wind turbines, aerodynamic coefficients, drag force, lift force, angle of attack, Reynolds number

\section{Introduction}

Renewable energy sources (RES) are sources of green, inexhaustible and increasingly competitive energy [1-4]. They differ from fossil fuels mainly in their diversity, abundance and potential for use anywhere in the world, but above all in that they do not produce greenhouse gases and atmospheric pollutants that cause climate change. The growth of clean energy sources is unstoppable, as reflected in statistics published annually by the International Energy Agency (IEA). Almost half of all new generating capacity installed in 2014, after coal, was obtained using RES [1]. According to the IEA, by 2040 the global demand for electricity will grow by $70 \%$ - its share in final energy consumption will grow from 18 to $24 \%$ [1]. As part of the development of a "green" economy and in order to reduce $\mathrm{CO}^{2}$ emissions, Kazakhstan continues to actively work on the development of RES [3]. Last year, projects with a total capacity of 45 MW were implemented in Kazakhstan. Currently, there are 89 renewable energy facilities in Kazakhstan with an installed capacity of $1022.1 \mathrm{MW}$, Table 1. Our country possesses significant RES, which include hydropower, wind and solar energy. It should be noted that all projects in the field of renewable energy in Kazakhstan are carried out at the expense of investors' own and borrowed funds and are not financed from the republican budget.

Table 1. Generation volume energy due to renewable energy sources in Kazakhstan in 2020 [4]

\begin{tabular}{|l|c|c|}
\hline \multicolumn{1}{|c|}{ Type of the renewable energy facilities } & Number & Installed capacity, MW \\
\hline Wind power plants & 26 & 404.4 \\
\hline Solar power plants & 42 & 891.6 \\
\hline Hydroelectric power plants & 37 & 224.6 \\
\hline Bioelectric power plants & 5 & 7.82 \\
\hline Total & 89 & 1022.1 \\
\hline
\end{tabular}


Wind energy is one of the fastest growing energy industries using RES. The world installed capacity of electric energy obtained by wind turbines (WPP) during period 2010 to 2020 increased from 177.193 MW to 698.909 MW, Fig.1. According to the last IRENA data [2], energy production from wind conversion doubled between 2009 and 2013.

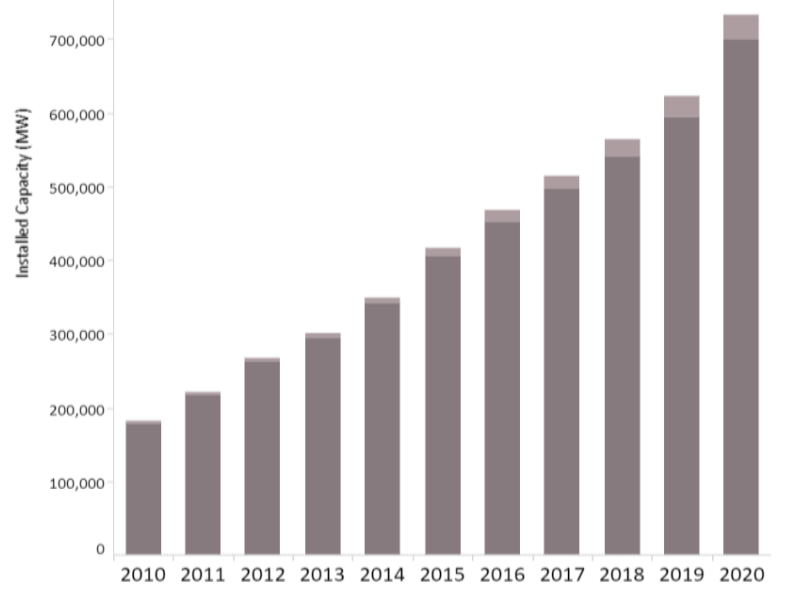

a)

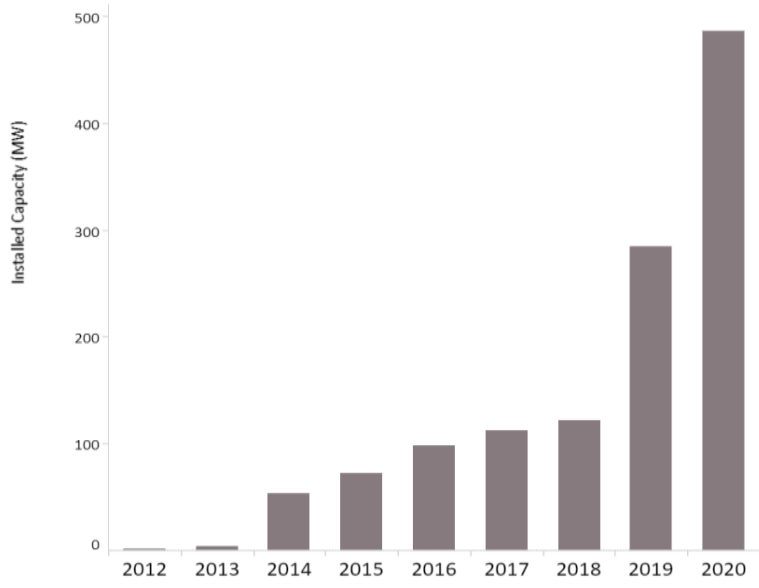

b)

Fig.1. Wind Energy data, installed capacity trends: a) by all countries in the World; b) in Kazakhstan [2].

Currently, the wind turbine market is diverse and large [2]. However, many existing installations with relatively low power ratings generate electrical power at free stream air velocities of $8-10 \mathrm{~m} / \mathrm{s}$. In areas with low-speed wind resources, most wind turbines do not work efficiently. The solution to this problem can be achieved by creating wind turbines that convert the energy of low-speed wind. It is known that wind turbines based on the Magnus effect are designed for low wind speeds [5-11]. A distinctive feature of these installations is the start-up and power generation at a free air speed of $2-3 \mathrm{~m} / \mathrm{s}$. The highest efficiency of wind turbines based on the Magnus effect is observed at speeds below $8 \mathrm{~m} / \mathrm{s}$ [7]. In this interval of wind speeds, the maximum power values were obtained, compared with bladed ones in wind turbines. The advantages of wind turbines based on the Magnus effect include the fact that their speed is 2-3 times less than that of bladed ones. This ensures the operational safety of wind turbines based on the Magnus effect.

Optimization of the performance and characteristics of the wind turbine based on the Magnus effect can be achieved by modifying the shapes and designs of the blades [9]. In this regard, a wind turbine is known, containing a wind wheel with a horizontal axis of rotation and radially mounted Magnus rotors in the form of cylinders, with an electric generator to drive the cylinders. Each rotor is made with a non-rotating root and rotating end parts and with a washer at the end of the blade [10]. In [11], a description of a wind turbine is given, in which a wind wheel with a horizontal shaft has radial blades in the form of cylindrical rotors with drives for their rotation. The disadvantages of these wind turbines are the complexity of the design of the blades, which increase the level of turbulence near the wind wheel, as well as the presence of drive motors with an additional source of energy. To increase the efficiency of wind power plants, it is necessary to optimize the power elements-blades. The aim of this work is to create a cylindrical blade with a deflector and study it's aerodynamics.

\section{Experimental part}

\subsection{The device of the turbo deflector}

The deflector is a mechanism that optimizes the air flow in order to increase the thrust $[12,13]$. A deflector is literally a guiding device, which is what defines its purpose. The dynamic deflector consists of a fixed base and a rotating turbine part, Fig. 2. The direction of the air flow occurs due to the creation of a low pressure area in the lower part of the installation. When the air flow around the deflector, a "vortex" is formed in the lower lobes and an auxiliary thrust appears. The greater the air flow, the draft from the inside of the apparatus is stronger. In other words, the deflector directs the wind parallel to the flow, thereby increasing thrust due to the pressure decreasing. The deflector reduces the likelihood of reverse thrust. The spherical part rotates in the same direction regardless of the direction of the wind vector. The elements of the 
spherical cap are made of light, thin metal, which allows the deflector with blades to turn on in operation with a slight wind - from $0.5 \mathrm{~m} / \mathrm{s}$.

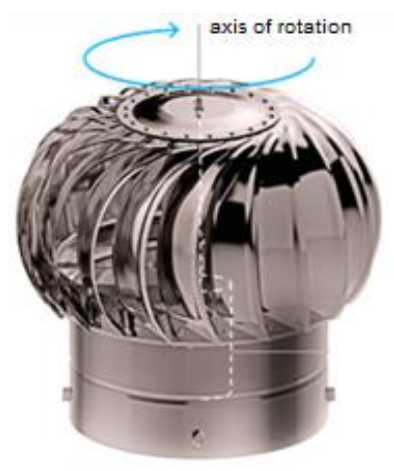

a)

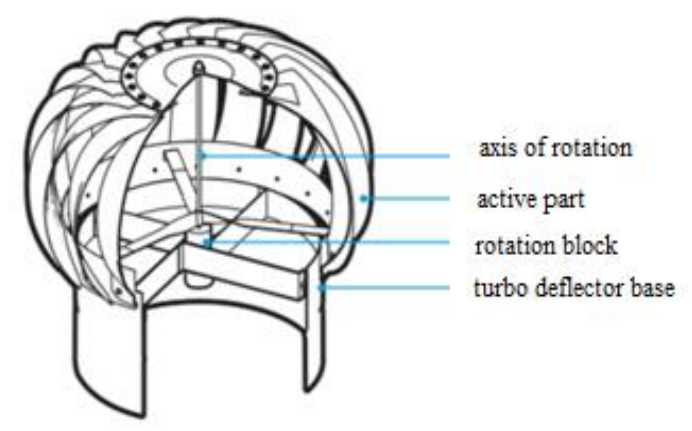

b)

Fig.2. Spherical turbo deflector: general view; device scheme [13].

In practice, a turbo deflector is used as an element of a ventilation system to effectively extract exhaust air from of rooms. TsAGI deflectors are widely known, which work without electricity consumption, using wind as the only source of energy [12]. In our study we used an active spherical deflector as an element of a cylindrical blade of a wind turbine based on the Magnus effect.

\subsection{Experimental technique}

Laboratory measurements of an experimental sample of a cylindrical blade with a turbo deflector were carried out at the Aerodynamics Laboratory of the Karaganda University named after E.A. Buketov. The regularities of aerodynamic characteristics, such as drag and lift forces, were studied in the open test section of the T-I-M wind tunnel, the scheme and parameters of the T-1-M installation were shown in detail in [7, 8]. The values of aerodynamic forces were measured using a three-component aerodynamic balance. To measure the air flow rate, a Skywatch Atmos cup anemometer was used, the error of which does not exceed $\pm 3 \%$. The experiments were carried out with the air flow velocity varied in the range from 3 to $15 \mathrm{~m} / \mathrm{s}$.

The experimental sample of the blade consists of a cylindrical element with a deflector rigidly fixed at the end (Fig.3). The active element of the blade is a turbo deflector, the petals of which open when exposed to an air flow, designed to provide an independent start of the rotation of a cylindrical blade. The angle of attack $\alpha$ was measured by comparison with rigid control (reference) instruments.

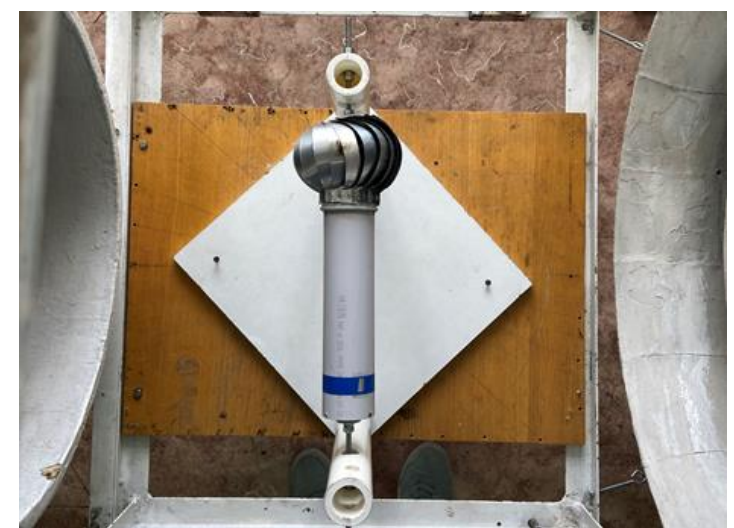

a)

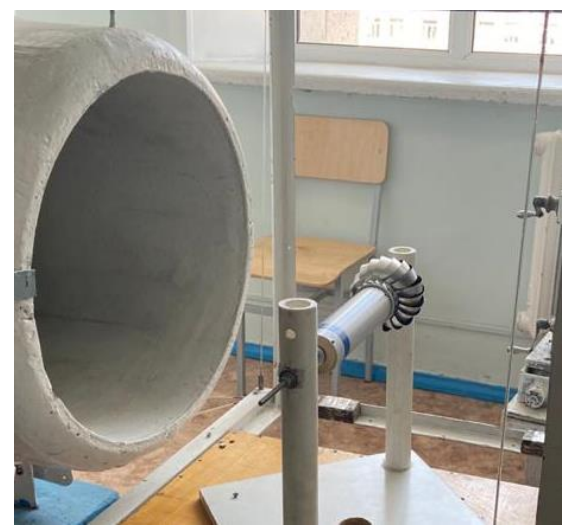

b)

Fig.3. Experimental model of a cylindrical blade with deflector in the working section of the wind tunnel:

a) top view; b) side view. Angle of attack $\alpha=0^{\circ}$

Geometrical parameters of a cylindrical blade with a deflector:

- the length of the cylindrical element - $\mathrm{L}=0.205 \mathrm{~m}$;

- cylinder radius $\mathrm{R}_{1}=0.025 \mathrm{~m}$;

- deflector radius $R_{2}=0.05 \mathrm{~m}$; 
The drag coefficient $\mathrm{C}_{\mathrm{x}}$ and lift coefficient $\mathrm{C}_{\mathrm{y}}$ had been calculated using standard formulas:

$$
\begin{gathered}
C_{x}=\frac{\Delta F_{x}}{\rho \cdot \frac{u^{2}}{2} \cdot S}, \\
C_{y}=\frac{\Delta F_{y}}{\rho \cdot \frac{u^{2}}{2} \cdot S}
\end{gathered}
$$

where $\Delta F_{x}$ is the force of frontal resistance, $[\mathrm{N}] ; \Delta F_{y}$ - is the lifting force, $[\mathrm{N}] ; \rho$ is the air density, $\rho=1.21$ $\left[\mathrm{kg} / \mathrm{m}^{3}\right] ; \mathrm{u}$ is the speed of the incoming air flow, $[\mathrm{m} / \mathrm{s}] ; \mathrm{S}$ is the area of the midsection, $\left[\mathrm{m}^{2}\right]$.

The experimental sample of the blade is a complexly connected element consisting of a cylinder with a spherical deflector. Therefore, the equivalent blade diameter $D$ had been calculated by formula:

$$
D=\left(\frac{L}{\sum_{i=1}^{n} \frac{l}{D_{i}^{5-m}}}\right)^{\frac{1}{5-m}},
$$

where $D_{i}$ is the diameter of each series-connected part of the blade, [m]; $l_{i}$ - section length, [m]; L - total length, [m]; $m$ is a dimensionless coefficient, which is 0.25 under turbulent mode for smooth surfaces blades.

Substituting the numerical value of $\mathrm{D}$, it is possible to determine the value of the blade midsection area $\mathrm{S}=0.0181 \mathrm{~m}^{2}$.

The Reynolds number was calculated by the formula:

$$
R e=\frac{\mathrm{u} \cdot \mathrm{D}}{\mathrm{v}}
$$

where $v$ is the coefficient of kinematic viscosity of air.

\section{Discussion of results}

As a result of the experiments carried out the aerodynamic coefficients of drag force and lift force of the experimental sample of a cylindrical blade were determined for different modes of air flow around the incoming air streams with a speed of (3-15) m / s. In fig. 4,5 show the values of the aerodynamic coefficients from the Reynolds number when the angles of attack $\alpha$ change from $0^{\circ}$ (the direction of the air flow is perpendicular to the axis of the cylindrical blade) to $60^{\circ}$. As a result of the study, it was found that the optimal angle of attack is $\alpha=0^{\circ}$ for the transverse direction of the air flow.

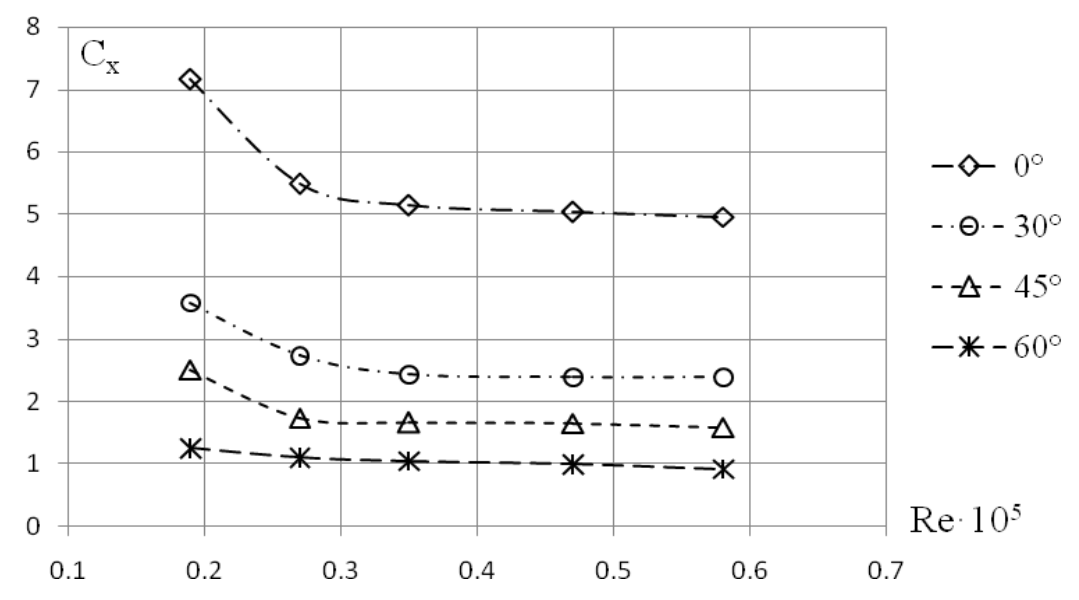

Fig.4. Dependence of the aerodynamic drag coefficient of a cylindrical blade with a deflector on the Reynolds number at different angles of attack $\alpha$ 


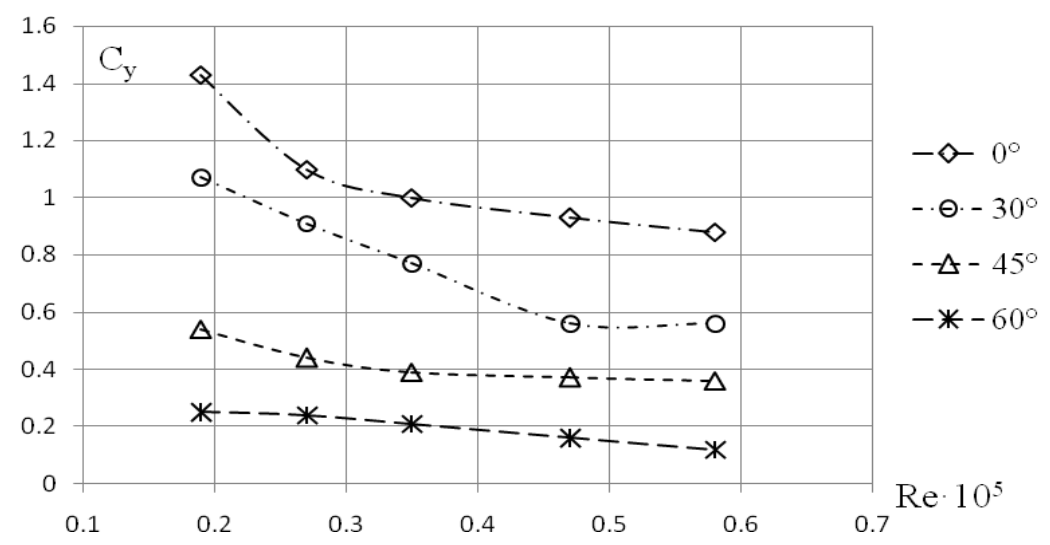

Fig.5. Dependence of the aerodynamic the lift coefficients of a cylindrical blade with a deflector on the Reynolds number at different angles of attack $\alpha$

The optimal values of the drag coefficient $C_{x}=7.16$ and lift coefficient $C_{y}=1.43$ at $\operatorname{Re}=0.19 \cdot 10^{5}$ and the angle of attack $\alpha=0^{\circ}$ have been established. It can be seen from the graphs that with an increase in the value of the angle of attack, the values of the aerodynamic coefficients decrease by approximately 1.5 times.

\section{Conclusions}

Within the framework of study a combined blade, consisting of a cylindrical element with a spherical turbo deflector, was developed and created. The description of the main parameters of the deflector, which creates additional thrust due to the turbulence of the flow, is given. At the initial stage, laboratory tests in a wind tunnel with an open working part of a cylindrical blade were carried out. The dependences of aerodynamic forces were obtained at different angles of attack and different air flow velocities. Experiments carried out many times show that the use of a deflector does not significantly affect the regularities of changes in aerodynamic forces and, accordingly, on the dynamics of aerodynamic coefficients. The use of a spherical turbo deflector at the end of a cylindrical blade can provide self-starting and starting rotation at low air flow velocities.

\section{REFERENCES}

1 Renewables 2020 Analysis and forecast to 2025. Fuel report - November 2020. Available at: www.iea.org/

2 International Renewable Energy Agency. Future of wind. Deployment, investment, technology, grid integration and socio-economic aspects. 2020, 88p. Available at: www.irena.org/wind

3 Lim N. Renewable Energy Sources Market in Kazakhstan: potential, challenges and prospects" as of the end of 2020. Available at: www.pwc.com/kz/en/assets/pdf/esg-dashboard-final-5.pdf

4 In 2021 Kazakhstan will build "green" power plants. Eenergy. media. Available at: www.astanasolar/en/news/

5 Bychkov N.M., Dovgal A.V., Kozlov V.V. Magnus wind turbines as an alternative to the blade ones. Journal of Physics: Conference Series. 2007, Vol. 75, pp. 012004.

6 Bychkov N.M. Wind turbine with the Magnus effect. 3. Design characteristics of the wind wheel. Teplofizika $i$ aeromekhanika, 2008, Vol.15, No. 2, pp. 341-352.

7 Kusaiynov K., et al. Experimental research of aerodynamics of the system of the revolved cylinders in a turbulent stream. Proceedings of the 7th Intern. Symp. on Turbulense, Heat and Mass Transfer. 2012, pp. 577 - 580.

8 Sakipova S.E., Tanasheva N.R., Kivrin V.I., et al. Study of wind turbine model aerodynamic characteristics with a rotating cylinder. Eurasian phys. tech. j. 2016, Vol.13, No.2 (26), pp.112-117.

9 Sakipova S.E., Tanasheva N.K. Modeling aerodynamics of the wind turbine with rotating cylinders. Eurasian phys. tech. j. 2019, Vol.16, No. 1(31), pp. 88 - 93.

10 Bychkov N., Sorokin A., Nobukhiro M. Wind turbine, Russian Patent RF238138. Bull. 4, Publ.10.02.2010, 6 p.

11 Komarova N.M. Power plant with an active method of wind processing based on the Magnus effect. Russian Patent RF 2327898. Publ. 27.06.2008, 11p.

12 Delyudin A. Ventilation deflector: device, types, installation rules. Available at: www.sovet-ingenera.com/vent /oborud/ventilyacionnyj-deflektor.html (Aug. 2019)

13 Aprelev E. Deflector ventilation TsAGI: features of calculation and manufacturing. Available at: www.ventil ationpro.ru/vytyazhnaya-ventilyatsiya/deflektor-ventilyacionnyjj-cagi-osobennosti-rascheta/ (14.05.2018) 